КАРАСЕВА Анна Константиновна - магистр по направлению «Психолого-педагогическое образование», Московский государственный психолого-педагогический университет (127051, Россия, 2. Москва, ул. Сретенка, 29; апnа.carasewa@yandex.ru)

\title{
ЦЕННОСТНЫЕ ОРИЕНТАЦИИ И РОДИТЕЛЬСКОЕ ОТНОШЕНИЕ К ДЕТЯМ В СЕМЬЯХ РАЗНОГО ВЕРОИСПОВЕДАНИЯ
}

\begin{abstract}
Аннотация. В статье представлен анализ результатов эмпирического изучения ценностных ориентаций и родительского отношения к детям в семьях разного вероисповедания. В качестве респондентов выступили матери из 50 православных, 50 иудейских и 50 мусульманских семей. В каждой семье на момент исследования воспитывались дети подросткового возраста. Исследование показало наличие особенностей в ценностных ориентациях и родительском отношении к детям, которые воспитываются в семьях разного вероисповедания. Подходы матерей разного вероисповедания к воспитанию детей связаны с характерными для исповедуемых ими религий ценностными ориентациями. Обнаружена взаимосвязь между родительским отношением к детям в семьях разного вероисповедания и их ценностными ориентациями.
\end{abstract}

Ключевые слова: ценностные ориентации, родительское отношение, иудеи, мусульмане, православные, вероисповедание

Введение. Семейные отношения - это основа, на которую опирается общество, именно в семье зарождаются общепринятые впоследствии культурные и моральные ценности. Общество все быстрее становится унифицированным, но семьи по-прежнему остаются очень различными по своей культуре и традициям. Для достижения точки взаимопонимания и уважения важно понимать и принимать самобытность народов. Семья является основным носителем культурных стереотипов, традиций и образцов, которые наследуются из поколения в поколение. Семья транслирует человеку особенности поведения, знакомит его с социальными ролями, в семье происходит выбор этой роли. Семья - это не только группа людей, часть общества, она может рассматриваться и как структурный элемент [Аликанова 2004: 26]. В психологии ценностные ориентации - это система ценностей, представляющая собой совокупность установок человека на те или иные ценности материальной или духовной культуры общества. Они создаются в процессе воспитания, целенаправленного развития, влияния общества на человека, т.е. по сути - это продукт социализации. Ценностные ориентации непосредственно влияют на особенности взаимодействия человека с окружающим его миром, в частности на социальные отношения, выбор профессиональной деятельности, способы построения коммуникаций с людьми. Родительское отношение оказывает непосредственное влияние на формирование ценностей человека. Ценностные ориентации самих родителей определяют в свою очередь их отношение к детям [Архангельский 2007: 30]. В этом процессе важную роль играет культура и религия. Религиозная направленность, принадлежность к определенной религии оказывает детерминирующее влияние на ценности [Арсалиев, Керимова, Эхаева 2014: 56].

Существует множество исследований, посвященных ценностным ориентациям, родительскому отношению к детям в семьях разного вероисповедания. Однако стоит отметить отсутствие достаточного числа исследований в направлении изучения влияния ценностных ориентаций на родительское отношение 
к детям старшего школьного возраста в семьях разного вероисповедания. В связи с этим данное исследование является актуальным в настоящее время.

Система ценностных ориентаций является наиважнейшей содержательной стороной направленности личности и основой ее взглядов на окружающий мир, на других людей, саму себя, ее мировоззрения, ядра мотивации и «философии жизни». Ценностные ориентации - способ разграничения объектов действительности по степени их значимости (положительной или отрицательной). Запаздыванию социальной зрелости у ребенка может способствовать такая родительская позиция, как чрезмерное оберегание [Коновалова 2017: 64]. У ребенка может сформироваться чрезмерная самоуверенность и необоснованно завышенное мнение о своей личности, непомерная требовательность, дерзость и даже тирания по отношению к родителям, что является одной стороной медали. С другой стороны, может появиться беспокойство, не проходящее и навязчивое чувство тревоги, боязнь, пассивность, отсутствие инициативы, податливость и поведение типа «избалованное дитя» при существовании зависимости от матери или отца [Куломзина 2008: 78]. Когда отношение родителей и ребенка построены на разумном доверии, когда в подростке воспитывается свободная личность, только тогда он может свободно и открыто общаться с ровесниками, быть находчивым, остроумным, сообразительным, самоуверенным в меру и будет способен разобраться в самых порой непредсказуемых различных общественных ситуациях.

Особенность воспитания ребенка в чеченской семье отражена в народном высказывании, которое звучит следующим образом: «Любой ребенок, который не достиг пятилетнего возраста, - это царь, с 5 до 15 лет ребенок проживает жизнь раба и далее становится другом» [Битарова 2002: 47]. Основополагающим в воспитании чеченцев можно считать непрестанность и естественность. В воспитании ребенка одной семьи имеют право участвовать все представители чеченского народа - данной национальности присущ феномен «народного воспитания». Это подразумевает, что на разных уровнях и в разной степени в процессе воспитания участие принимает и семья, и вся этническая общность [Комиссарова 2007: 322]. Это обеспечивает связь поколений, неразрывность передачи культурных и этнических традиций. Почитание старших, дань уважения предкам - основополагающая часть культуры чеченского народа. Беспрекословное повиновение старшим членам семьи, отсутствие возможности ослушаться, вступать в конфликты с ними - нерушимые правила внутри семьи и народа в целом. Несмотря на современные изменившиеся условия существования народа, наиболее широкие рамки свободы, данные правила являются основными для чеченской семьи, им уделяется особое внимание в процессе воспитания детей [Марван 1997: 14]. За непослушание в вопросах уважения к старшим и почитания традиций следуют серьезные наказания, в т.ч. и телесные. Согласно Корану, особое почтение и уважение в семье отводится матери, несмотря на то что главой семьи традиционно является мужчина. Неуважение, проявленное по отношению к матери, - страшный проступок и грех. В исламе наиболее важным считается вырастить ребенка благодарным и полным уважения к своим корням, ставящим во главу угла свою семью [Нунуев 2008: 114]. Семья имеет наибольший вес в обществе для мусульманина. Также большое внимание уделяется воспитанию милосердия в детях. Воспитание в чеченских семьях имеет свод жестких правил, но, несмотря на это, каждый ребенок в семье имеет свои права, ограниченные тем, какого пола ребенок - мальчик или девочка. Такие же различия имеются и в обязанностях детей в семье [Саракаева 2013: 49].

Еврейское воспитание подразумевает необходимость следования тем прин- 
ципам нахождения гармонии и терпения внутри себя и внутри супружеской пары, которые указаны в Торе. И именно это будет помощью всем членам семьи [Рав Реувен Пятигорский 2019: 9]. Также родителям рекомендуется начать с себя - быть примером и самому следовать правилам, устанавливаемым в семье. Телесные наказания допустимы, но с большими оговорками и предостережениями. Как правило, прибегать к телесным наказаниям в еврейских семьях не считается нормальным. Особенности воспитания внутри еврейских семей сводятся на практике к прививанию хороших привычек [Рабинович 2015: 39]. С раннего детства формируются правильные представления о себе и окружении, последовательность действий в различных ситуациях. Данные привычки и особенности должны быть растолкованы ребенку так, чтобы впоследствии они не вызывали у него дискомфорт или ощущение ограниченности в свободе [Зарин, Кэмен, Векслер 2013: 139].

Несмотря на существующие различия в воспитании детей в еврейских и чеченских семьях, можно говорить о том, что основной целью и в тех и в других семьях является воспитание детей в традициях своего народа, которое направлено на привитие им хороших и необходимых навыков и привычек для дальнейшей их жизни в многоконфессиональном обществе.

Обобщая вышеизложенное, стоит отметить, что ценностные ориентации это наиболее важная содержательная сторона направленности личности, определяющая систему взглядов на мир и положение в социуме. Мысли и решения человека, его жизненная философская система представлений, грань допустимого и недопустимого определяются важными для него человеческими ценностями. Ценностные ориентации по-своему разграничивают для личности грани дозволенного, определяют градацию значимости, выделяют или подавляют эмоции и чувства, раскрашивают положительными или отрицательными красками тот или иной объект. Системой ценностных ориентаций зрелая личность владеет в полном объеме. Семья оказывает непосредственное влияние на формирование ценностей [Павлова 2013: 119]. Запаздыванию социальной зрелости ребенка может способствовать чрезмерное родительское оберегание. Такая родительская позиция может привести к формированию у ребенка чрезмерной самоуверенности, необоснованно завышенному мнению о своей личности, непомерной требовательности, дерзости, возможно даже тирании в отношениях внутри семьи. С другой стороны, такая родительская позиция приводит к появлению у ребенка беспокойства, навязчивого чувства тревоги, боязни, пассивности, безынициативности, формируется острая зависимость от матери или отца. Основой гармоничного развития ребенка является базовое разумное доверие внутри семьи [Хребина, Швалева, Ваделова 2018: 629]. Отношения между родителями и детьми, не обременяющие участников этих отношений, не разрушающие эмоциональный фон и не приносящие тревогу и страх, помогают правильно сформировать человеческие ценности у ребенка. В доверительных отношениях с родителями ребенок раскрывает в себе свободную личность, которая в меру уверена в своих силах, правильно выстраивает общение с социумом и может найти выход из любой общественной ситуации, зная, что трудности, непосильные ему, он всегда может разделить со своей семьей [Хуриева 2014: 59].

Существует множество различий в воспитании детей в семьях разных конфессий. Рассмотренные в данном исследовании еврейские и чеченские семьи имеют ряд культурных особенностей, в корне различающихся, влияющих на формирование личности ребенка в семье. Однако стоит обратить внимание, что, несмотря на ряд существующих различий, воспитание в семьях разных вероисповеданий имеет общую цель. Этой целью является сохранение в про- 
цессе воспитания традиций и правил своего народа, и одновременно с выполняется задача привить детям навыки и привычки, которые помогли бы им общаться и самореализоваться в современном многоконфессиональном обществе.

\section{Описание программы исследования.}

Цель нашего исследования: изучить специфику ценностных ориентаций и родительского отношения в семьях разного вероисповедания. Для этого мы использовали следующие методики: «Взаимодействие родитель-ребенок» И.М. Марковской; «Экспериментальное исследование особенностей эмоциональной стороны детско-родительского взаимодействия» Е.И. Захаровой; тест «Смысложизненные ориентации» (СЖО) Д.А. Леонтьева [Марковская 2000: 109; Захарова 2002: 114; Леонтьев 2003: 97].

Объект исследования: ценностные ориентации и родительское отношение к детям.

Предмет исследования: ценностные ориентации и родительское отношение к детям в православных, мусульманских и иудейских семьях.

Гипотеза исследования: родительское отношение к детям в семьях разного вероисповедания связано с ценностными ориентациями.

Для анализа результатов исследования использовались методы статистической обработки данных: количественный анализ $U$ Манна-Уитни, $H$ КраскелаУоллиса и коэффициент ранговой корреляции $\rho$ Спирмена, описательная статистика с помощью одновыборочного критерия Колмогорова-Смирнова, критерия $\chi^{2}$ Пирсона и корреляционного анализа. Для проверки гипотезы в качестве испытуемых выступили 50 православных, 50 иудейских и 50 мусульманских семей, в которых воспитываются дети среднего школьного возраста. Возраст респондентов - от 34 до 52 лет. Подавляющее большинство респондентов воспитывают двоих детей. По одному ребенку воспитывают 3 еврейских и 5 православных матерей.

Результаты исследования.
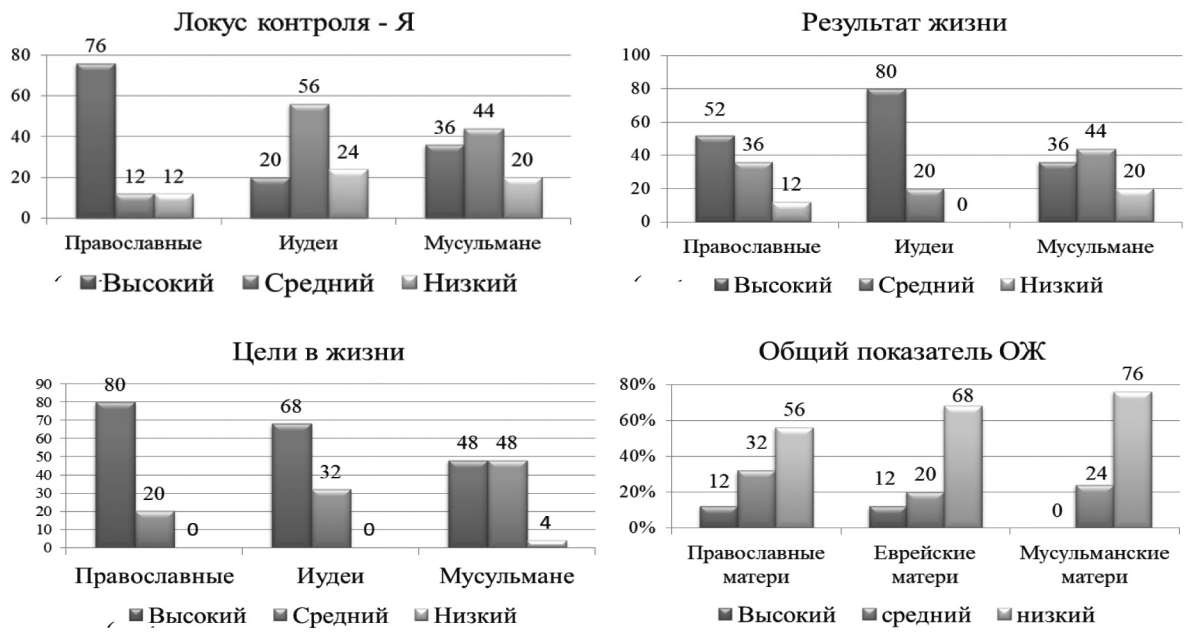

Рисунок 1. Результаты изучения смысложизненных ориентаций матерей разного вероисповедания по методике Д.А. Леонтьева 
Таблииа 1

Обобщенная таблица, отражающая различия между сравниваемыми группами (по критерию $\chi^{2}$ Пирсона)

\begin{tabular}{|l|c|c|c|}
\hline \multirow{2}{*}{ Шкала СЖО } & \multicolumn{3}{|c|}{ Различия между сравниваемыми группами $\left(\chi^{2}\right)$} \\
\cline { 2 - 4 } & иудеи / мусульмане & иудеи / православные & $\begin{array}{c}\text { православные / } \\
\text { мусульмане }\end{array}$ \\
\hline Цели & 2,662 & 0,936 & 5,882 \\
\hline Результативность & $8,889^{*}$ & 0,833 & $8,400^{*}$ \\
\hline Процесс & $8,665^{*}$ & 0,393 & 5,658 \\
\hline ЛК - Я & $7,554^{*}$ & $16,284^{* *}$ & 2,258 \\
\hline ЛК - жизнь & $7,193^{*}$ & $21,310^{* *}$ & $6,923^{*}$ \\
\hline Общая ОЖ & 3,202 & $7,503^{*}$ & $10,681^{* *}$ \\
\hline
\end{tabular}

Примечание: * - различия значимы на уровне $\mathrm{p} \leqslant 0,05 ; * *-$ различия значимы на уровне $\mathrm{p} \leqslant 0,01$.

Из диаграмм по результатам теста «Смысложизненные ориентации» Д.А. Леонтьева (рис. 1) видно, что имеются различия по подавляющему большинству шкал методики, а именно:

- в православных семьях показатель по шкалам «Цели жизни» и «Локус контроля - Я» является самым высоким;

- в иудейских семьях наиболее высокий показатель наблюдается по шкале «Результат жизни»;

- во всех группах испытуемых наиболее низкие показатели - по субшкале «Общий показатель ОЖ» (см. табл. 1).
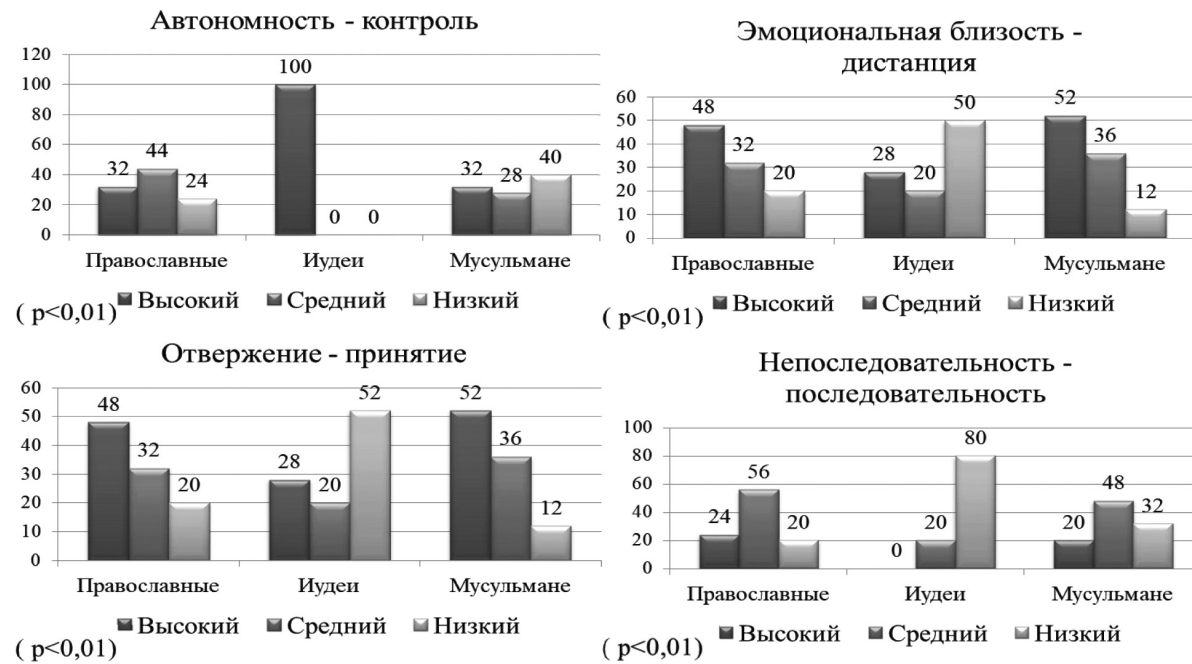

$(\mathrm{p}<0,01) \square$ Высокий $\square$ Средний $\square$ Низкий

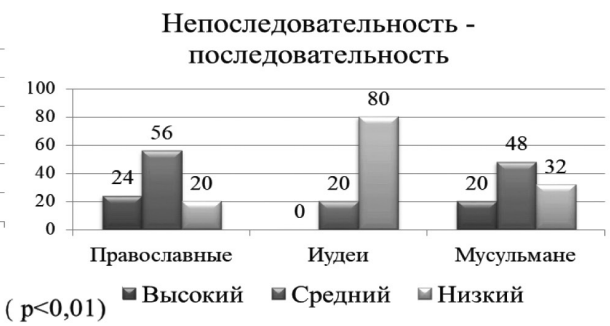

Рисунок 2. Методика «Взаимодействие родитель-ребенок» И.М. Марковской

Результаты проведения методики И.М. Марковской показали значимые различия по шкалам, представленным на рис. 2 и в табл. 2. Анализ данных мето- 
Таблица 2

Родительское отношение в семьях с разным вероисповеданием по шкалам методики «Взаимодействие родитель-ребенок» И.М. Марковской (по критерию $\chi^{2}$ Пирсона)

\begin{tabular}{|c|c|c|c|c|c|}
\hline \multirow{2}{*}{ Переменные } & \multicolumn{3}{|c|}{ Вероисповедание (средние ранги) } & \multirow{2}{*}{$\chi^{2}$} & \multirow{2}{*}{$\mathbf{p}$} \\
\hline & иудеи & православные & мусульмане & & \\
\hline Автономность-контроль & 26,82 & 60,1 & 27,08 & 38,960 & $0,000 * *$ \\
\hline $\begin{array}{l}\text { Эмоциональная } \\
\text { дистанция-близость }\end{array}$ & 41 & 26,96 & 46,04 & 10,472 & $0,005^{* *}$ \\
\hline Отвержение-принятие & 44,98 & 52,56 & 16,46 & 38,462 & $0,000^{* *}$ \\
\hline $\begin{array}{l}\text { Непоследовательность- } \\
\text { последовательность }\end{array}$ & 45,9 & 22,78 & 45,32 & 18,452 & $0,000^{* *}$ \\
\hline
\end{tabular}

Примечание: ** - различие значимо на уровне $\mathrm{p} \leqslant 0,01 ; *$ - различие значимо на уровне $\mathrm{p} \leqslant 0,05$

дики показывает особенности воспитания в различных семьях: так, в православных семьях наиболее важным в родительском отношении к детям является согласованность взаимодействия родителей и детей. Не столь важным для матерей в семьях православного вероисповедания кажется последовательность и постоянство в требованиях по отношению к ребенку. У матерей из иудейских

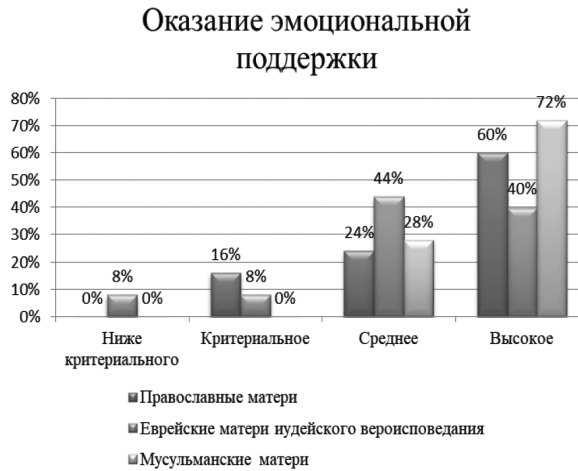

Понимание причин состояния

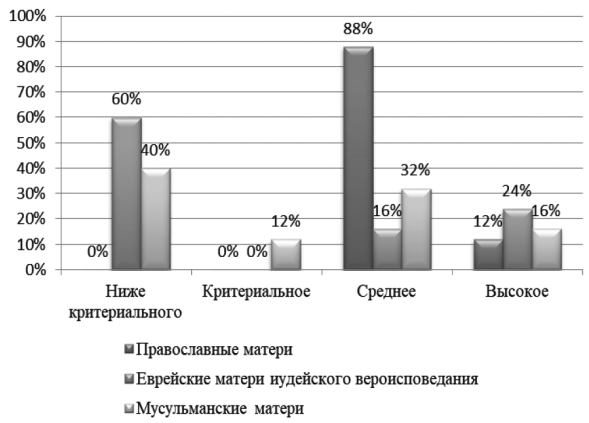

Принятие себя в качестве родителя

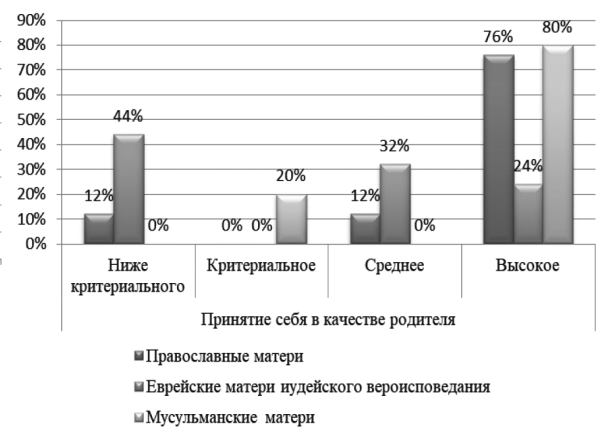

Безусловное принятие

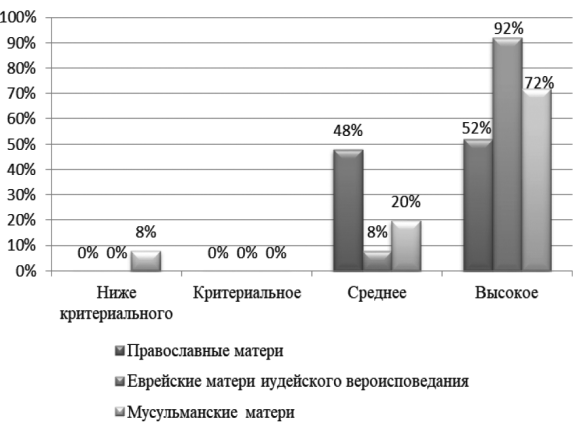

Рисунок 3. «Экспериментальное исследование особенностей эмоциональной стороны детско-родительского взаимодействия» по методике Е.И. Захаровой 
семей доминирует контроль в воспитании детей. Менее важным для матерей в этих семьях считается последовательность (как и в православных семьях), авторитетность и удовлетворенность своими отношениями с детьми. В мусульманских семьях на первом месте присутствует строгость. Рядом по значимости - близость и принятие. Вовлеченность ребенка в совместные действия менее значима для мусульманских матерей.

Таблица 3

Попарное сравнение особенностей эмоциональной стороны детско-родительского взаимодействия по методике Е.И. Захаровой семей с разным вероисповеданием (по критерию U Манна-Уитни)

\begin{tabular}{|c|c|c|c|c|}
\hline \multirow{2}{*}{ Переменные } & \multicolumn{2}{|c|}{$\begin{array}{c}\text { Вероисповедание } \\
\text { (средние ранги) }\end{array}$} & \multirow[t]{2}{*}{$U$} & \multirow{2}{*}{$\rho$} \\
\hline & православные & мусульмане & & \\
\hline Понимание причин состояния & 29,58 & 21,42 & 210,5 & $0,043^{*}$ \\
\hline Отвержение-принятие & 34,54 & 16,46 & 86,5 & $0,000^{* *}$ \\
\hline \multirow{2}{*}{ Переменные } & \multicolumn{2}{|c|}{$\begin{array}{c}\text { Вероисповедание } \\
\text { (средние ранги) }\end{array}$} & \multirow[t]{2}{*}{$\boldsymbol{U}$} & \multirow{2}{*}{$\rho$} \\
\hline & иудеи & мусульмане & & \\
\hline Принятие себя в качестве родителя & 18,44 & 32,56 & 136 & $0,001^{* *}$ \\
\hline Оказание эмоциональной поддержки & 20,9 & 30,1 & 197,5 & $0,025^{*}$ \\
\hline \multirow[t]{2}{*}{ Переменные } & \multicolumn{2}{|c|}{$\begin{array}{l}\text { Вероисповедание } \\
\text { (средние ранги) }\end{array}$} & \multirow[t]{2}{*}{$U$} & \multirow[t]{2}{*}{$\rho$} \\
\hline & иудеи & православные & & \\
\hline Понимание причин состояния & 31,04 & 19,96 & 174 & $0,006^{* *}$ \\
\hline Безусловное принятие & 21,28 & 29,72 & 207 & $0,035^{*}$ \\
\hline Принятие себя в качестве родителя & 31,64 & 19,36 & 159 & $0,003^{* *}$ \\
\hline $\begin{array}{l}\text { Ориентация на состояние ребенка } \\
\text { при построении взаимодействия }\end{array}$ & 32,52 & 18,48 & 137 & $0,001^{* *}$ \\
\hline
\end{tabular}

Примечание: * - различие значимо на уровне $\mathrm{p} \leqslant 0,05$; ** - различие значимо на уровне $\mathrm{p} \leqslant 0,01$

На основании представленных на рис. 3 и в таблице 3 результатов исследования эмоциональной составляющей детско-родительских отношений можно определить градацию наиболее важных для каждой группы испытуемых эмоциональных составляющих детско-родительских отношений. Православные семьи на первое место ставят понимание причин состояния ребенка. На втором месте - способность воспринимать состояние. На третьем - оказание эмоциональной поддержки и ориентация на состояние ребенка при построении взаимодействия.

В иудейских семьях приоритетным является безусловное принятие. На второе место матери поставили чувства родителей. Такие же результаты и по шкале, представляющей стремление к телесному контакту. Третье место по значимости у матерей данной группы отдано умению воздействовать на эмоциональное состояние ребенка, способности воспринимать состояние и эмпатии.

Для матерей в мусульманских семьях на первом месте - оказание эмоциональной поддержки и принятие себя в качестве родителя. На втором месте для матерей располагаются чувства родителей. На третье место мусульманские матери ставят безусловное принятие. 
Интерпретация результатов исследования. Уровень осмысленности жизни матери влияет на чувства, которые она испытывает в процессе взаимодействия с ребенком, на то, как часто у нее возникает потребность к телесному контакту с ним в ситуации взаимодействия, ориентируется ли она на состояние ребенка при построении взаимодействия. Когда мать живет сегодняшним днем и воспоминаниями о прошлой жизни, требовательность и строгость по отношению к ребенку возрастают. Чем выше результаты по шкале «Цели в жизни», тем выше и результаты по шкалам «Чувства родителей в ситуации взаимодействия», «Стремление к телесному контакту» и «Ориентация на состояние ребенка при построении взаимодействия» и ниже по шкалам «Нетребовательность-требовательность» и «Мягкость-строгость». Чем более эмоционально насыщена и наполнена смыслом жизнь матери, тем чаще она стремится к телесному контакту со своим ребенком. Шкала «Процесс жизни» положительно коррелирует со «Стремлением к телесному контакту». Неверие в свои силы по контролю над событиями собственной жизни влияет на способность матери воспринимать состояние ребенка. Шкала «Локус контроля - Я» коррелирует со «Способностью воспринимать состояние» и «Ориентацией на состояние ребенка при построении взаимодействия». Убежденность в том, что возможно контролировать свою жизнь, свободно принимать решения и воплощать их в жизнь, также влияют на потребность телесного контакта с ребенком и ориентацию на состояние ребенка при построении взаимодействия. Шкала «Локус контроля - жизнь» коррелирует со шкалами «Стремление к телесному контакту» и «Ориентация на состояние ребенка при построении взаимодействия».

Заключение. Результаты изучения теоретических материалов указывают на основные факторы сохранения психологического здоровья ребенка. Это адекватное родительское отношение с разумным подходом к воспитанию детей и само поведение родителей как образец для подрастающего поколения. Сложность и многогранность подходов к воспитанию детей в различных семьях не позволяет до конца четко структурировать детско-родительские отношения. В семьях разной национальности и вероисповедания есть свои особенности воспитания детей. Они многогранны, имеют похожие и непохожие черты. Однако неизменным положительным фактором воспитания является доверительное отношение родителей к ребенку. Тогда в подростке воспитывается свободная личность, которая в состоянии сделать выбор, решить конфликтную ситуацию с умом, выбрать свой жизненный путь, опираясь на свои ценностные ориентации, привитые ему в семье. Тогда ребенок будет способен разбираться в самых разных общественных ситуациях и стать взрослым. Эмпирическое исследование показало, что доминирующие позиции в исследуемых этнических группах имеют сходства и различия как в ценностных ориентациях матерей, так и в родительском отношении к детям. Результаты, которые были получены по итогам исследования, подтверждают выдвинутое предположение о существующих различиях в родительском отношении к детям в семьях разного вероисповедания.

\section{Список литературы}

Аликанова Р.А. 2004. Этнопедагогический потенциал чеченской семьи: дис. ... к.пед.н. Грозный. 200 с.

Арсалиев Ш.М.-Х., Керимова М.М., Эхаева Р.М. 2014. Этнопедагогика чеченцев и проблемы нравственного воспитания. Грозный: Изд-во ЧГУ. 226 с.

Архангельский Л.М. 2007. Ценностные ориентации и нравственное развитие личности. М.: Знание. 64 с. 
Битарова А.Т. 2002. Этикет горских народов Северного Кавказа и его влияние на воспитание подрастающего поколения: дис. ... к.пед.н. Владикавказ. 170 с.

Захарова Е.И., Карабанова О.А. 2002. Экспериментальные исследования особенностей эмоциональной стороны детско-родительского взаимодействия: Возрастно-психологический подход в консультировании детей и подростков. M. $416 \mathrm{c}$.

Зарин Д., Кэмен Г., Векслер Л. 2013. Секреты еврейской матери. Искренние советы, реальные истории, подлинная любовь (пер. Н. Новикова). М.: Карьера Пресс. 352 c.

Комиссарова Е.В. 2007. Содержание, средства, методы и приемы воспитания подрастающих поколений в народной педагогике горцев. - Известия Российского государственного педагогического университета им. А.И. Гериена. № 53. C. 321-323.

Коновалова А.Н. 2017. Психологическое содержание уважения к родителям в подростковом возрасте: дис. ... к.пед.н. М. 269 с.

Куломзина С.С. 2008. Наша Церковь и наши дети: Христианское воспитание детей в современном мире (пер. с англ. С.С. Бычкова). М.: Образ. 192 с.

Леонтьев Д. А. 2003. Психология смысла. М.: Смысл. 169 с.

Марван Ибхарим ал-Кайси Абу Аиша. 1997. Исследования о семье в Исламе. M. 20 c.

Марковская И.М. 2000. Тренинг взаимодействия родителей с детьми. СПб: Речь. 150 с.

Нунуев С.М. 2008. Чеченцы. М.: Глосс-пресс. 250 с.

Павлова О.С. 2013. Чеченский этнос сегодня: черты социально-психологического портрета. М.: Сам Полиграфист. 558 с.

Рабинович С. 2015. Еврейские дети любят свою маму. М.: АСТ. 100 с.

Рав Реувен Пятигорский. 2019. Традиции еврейского воспитания. Доступ: https://toldot.ru/blogs/pyatigorsky/pyat_106.html (проверено 07.05.2021).

Саракаева А.X. 2013. Традиции и обычаи чеченцев как этнопедагогические приниипы воспитания молодого поколения: дис. ... к.пед.н. Владикавказ. 168 с.

Хребина С.В., Швалева Н.М., Ваделова Х.Ю. 2018. Ролевая структура в мусульманских семьях с различным типом функционирования. - Minbar. Islamic Studies. T. 11. № 3. C. 621-634.

Хуриева М.Ю. 2014. Педагогические идеи и опыт «материнского» и «отиовского» воспитания народов Северного Кавказа и их использование в современных условиях: дис. ... к.пед.н. Владикавказ. 223 с.

\section{VALUE-BASED ORIENTATIONS AND PARENTAL ATTITUDE TO CHILDREN IN FAMILIES OF DIFFERENT CONFESSIONS}

\footnotetext{
Abstract. The article presents an analysis of the results of an empirical research of the system of values and parental attitudes towards children in families of different confessions. The respondents of the research were mothers from 50 Orthodox, 50 Jewish and 50 Muslim families. At the time of the research in each of the family children of adolescent age were brought up. The research showed the presence of peculiarities in value orientations and parental attitude towards children who are brought up in families of different confessions. The approaches of women of different confessions to child-rearing
} 
practices are associated with distinctive aspects of the value-based orientations of their religions. The author finds out the correlation between parental attitudes towards their children in families of different confessions and their value orientations. Keywords: value orientations, parental attitude, Jew, Muslim, Orthodox, confession

СТРОГАНОВ Алексей Валерьевич - аспирант кафедры истории и регионоведения Московского гуманитарного университета (111395, Россия, г. Москва, ул. Юности, 5; stroganovalexey@yahoo.com)

\title{
РОЛЬ ДУХОВЕНСТВА В КРЕСТЬЯНСКОМ ПРОТЕСТЕ В ПЕРИОД КОЛЛЕКТИВИЗАЦИИ
}

\begin{abstract}
Аннотация. В статье представлена интерпретация взаимоотношений государственной власти и духовенства в условиях объявленного в СССР “великого перелома», положившего начало сплошной коллективизации. На основе архивных материалов и документальных изданий констатируется, что масштаб репрессий в отношении сельских священников несопоставим с таковым в начале 1930 г., следствием чего явился массовый протест духовенства против политики советской власти в отношении церкви. Однако борьба за существование с привлечением на свою сторону крестьянских масс нередко сочеталась с проявлениями покорности духовенства по отношению к репрессивной государственной политике. Ключевые слова: коллективизация, российская деревня, государство, власть, протест, сельское духовенство, церковь, крестьянство
\end{abstract}

B современной исторической литературе изучение различных сюжетов советской истории, имеющих трагическое содержание (в частности, история сталинизма), не сводится только к описанию конкретных фактов. Исследователи перешли к представлению отечественного опыта, основанного на исторических уроках: сегодня актуальна репрезентация закономерностей, тенденций, основанная на интерпретации, осмыслении, понимании событий, явлений, процессов прошлого [Васильев, Шепелев 2016].

Одной из таких тем является изучение взаимоотношений государственной власти и различных социальных слоев российской деревни. Феномен протеста российского духовенства в эпоху «великого перелома», объявленного в 1929 г., занял важное место в общей структуре сопротивления крестьянства проводимой Советским государством политике коллективизации сельского хозяйства, при этом очень часто становясь «мотором» общего протеста.

В письме В.И. Ленина членам политбюро ЦК ВКП(б) о политике в отношении церкви от 19 марта 1922 г. лидер правящей партии утверждал: Если необходимо для осуществления известной политической цели пойти на ряд жестокостей, то надо осуществлять их самым энергичным образом и в самый короткий срок» [Алешкин, Васильев 2012: 53-54].

С началом коллективизации некоторые церковные иерархи пытались умилостивить Советское государство. Так, в начале 1930 г. в Рязанский окружком Московской области поступила докладная записка, в которой упоминалось об обнаруженном письме рязанского архиерея, в котором он призывал священничество не выступать с проповедями против коллективизации и быть лояльными в отношении существующей власти ${ }^{1}$.

1 Рязанская деревня в 1929 - 1930 годах. Хроника головокружения: документы и материалы. М.: РОССПЭН. 1998. С. 203 с. 